\title{
Parametric neutronics analyses of lattice geometry and coolant candidates for a soluble-boron-free civil marine SMR core using micro-heterogeneous duplex fuel
}

\author{
Syed Bahauddin Alam ${ }^{\mathrm{a}, *}$, Cameron S. Goodwin ${ }^{\mathrm{b}}$, Geoffrey T. Parks ${ }^{\mathrm{a}}$ \\ ${ }^{a}$ Department of Engineering, University of Cambridge \\ Cambridge, CB2 1PZ, United Kingdom \\ ${ }^{b}$ Rhode Island Atomic Energy Commission \\ 16 Reactor Rd, Narragansett, RI 02882, USA
}

\begin{abstract}
Civilian marine reactors face a unique set of design challenges in addition to the usual irradiation and thermal-hydraulic limits affecting all reactors. These include requirements for a small core size, long core lifetime, a $20 \%$ cap on fissile loading, and limitations on the use of soluble boron. One way to achieve higher burnup/longer core life is to alter the neutron spectrum by changing the hydrogen-to-heavy-metal ratio, thus increasing the conversion of fertile isotopes in the fuel. In this reactor physics study, we optimize the two-dimensional lattice geometry of a 333 MWth soluble-boron-free marine PWR for $18 \%{ }^{235} \mathrm{U}$ enriched micro-heterogeneous $\mathrm{ThO}_{2}-\mathrm{UO}_{2}$ duplex fuel and $15 \%{ }^{235} \mathrm{U}$ enriched homogeneously mixed all- $\mathrm{UO}_{2}$ fuel. We consider two types of coolant: $\mathrm{H}_{2} \mathrm{O}$ and mixed $80 \% \mathrm{D}_{2} \mathrm{O}+20 \% \mathrm{H}_{2} \mathrm{O}$. We aim to observe in which spectrum discharge burnup is maximized in order to improve uranium utilization, while satisfying the constraint on moderator temperature coefficient. It is observed that higher discharge burnup for the candidate fuels is achievable by using either a wetter lattice or a much drier lattice than normal, while epithermal lattices are distinctly inferior performers. The thorium-rich duplex fuel exhibits higher discharge burnup potential than the all- $\mathrm{UO}_{2}$ fuel for all moderation regimes for both coolants. The candidate fuels exhibit higher initial reactivity and discharge burnup with the mixed $\mathrm{D}_{2} \mathrm{O}-\mathrm{H}_{2} \mathrm{O}$ coolant than with the $\mathrm{H}_{2} \mathrm{O}$ coolant in the under-moderated regime, whereas these values are lower for the $\mathrm{D}_{2} \mathrm{O}-\mathrm{H}_{2} \mathrm{O}$ coolant in the over-moderated regime.
\end{abstract}

Keywords: Civil marine propulsion, Small modular reactor, Soluble-boron-free operation, Micro-heterogeneous thorium-based duplex fuel, Lattice geometry optimization, Achievable discharge burnup, Initial reactivity, Conversion ratio, Moderator temperature coefficient.

\footnotetext{
${ }^{*}$ Corresponding author

Email address: syed.nuclear@cantab.net (Syed Bahauddin Alam)
} 


\section{Introduction}

3

Perhaps surprisingly, interest is presently being shown in the possible application of nuclear energy in marine propulsion and this topic has recently received renewed attention after many years of apparent neglect (Hirdaris et al., 2014, Ragheb, 2012, Carlton et al., 2011, Sawyer et al., 2008). Since 2002 there has been a resurgence of reconsidering the technical and economic feasibility of technology options for marine nuclear propulsion due to the environmental concerns and changes in market economics. A nuclear-powered ship - be it a surface ship or a submarine - receives its propulsion energy from a nuclear power plant on board, and can be dubbed an "atomic engine" (Ragheb, 2012). The main advantages of nuclear marine propulsion are that atomic engines do not consume hydrocarbon-based fuel and oxygen, and produce no exhaust gas (Ragheb, 2012). Atomic engines are reliable, compact sources of energy that can operate for years without new fuel (Hirdaris et al., 2014). These benefits have motivated the development of atomic engines without too much concern regarding cost (Hirdaris et al., 2014, Carlton et al., 2011, Sawyer et al., 2008). The employment of advanced reactors and a careful concentration on cost-conscious design can result in nuclear marine propulsion systems that are economically superior to conventional energy systems.

In an effort to decarbonise energy production and concerns about the effects of climate change, there is growing interest in the possibility of using nuclear propulsion systems (Kramer, 1962). Maritime shipping accounts for $\sim 3 \%$ of global $\mathrm{CO}_{2}$ emissions, and could account for $15-30 \%$ of all $\mathrm{CO}_{2}$ emissions permitted in 2050 as economic growth in the developing world increases the volume of international commerce. The current global shipping industry emits roughly $1 \mathrm{Gt} \mathrm{CO}_{2}$ about a third more than current aviation emissions. Without significant policy action, future projections of global maritime shipping emissions suggest that we are likely to be on a path that would lead to global shipping emissions of $\sim 3 \mathrm{Gt} \mathrm{CO}_{2}$ in 2050 . This would represent almost a threefold increase on today's levels $\left(1 \mathrm{Gt} \mathrm{CO}_{2}\right)$. Diesel shipping poses serious threats to the environment both on inland waterways and on the ocean. Most large ships emit significant amounts of sulphur and nitrous oxides from the combustion of heavy fuel oil, and it is expected that maritime sources will soon account for the majority of all $\mathrm{SO}_{x}$ and $\mathrm{NO}_{x}$ emissions in Europe (Otto, 2013, Hirdaris et al., 2014). These pollutants are solely responsible for additional health costs of tens of billions of euros associated with heavy maritime traffic (Otto, 2013, Schinas and Stefanakos, 2012). Since nuclear fission produces no direct emissions, it clearly enjoys key environmental advantages over current diesel engines.

Considering the non-proliferation issues associated with naval reactors, a major loophole has been created by the Non-Proliferation Treaty (NPT) of nuclear weapons which allows a non-nuclear-weapon country to avoid international safeguards governing highly enriched weapon-grade fissile materials if it claims that the materials will be used for a nuclear marine propulsion program (McCord, 2013, Harvey, 2010). Therefore, a non-nuclear-weapon country can produce or stockpile weapons-grade highly enriched uranium (HEU) for a nuclear marine propulsion core to be constructed in the future, which can then potentially be used for the production of nuclear weapons. Concerns regarding nuclear weapons proliferation 
have significantly increased since some countries have sought to develop new nuclear energy programs, and it is well known that these countries can use centrifuges to make HEU more easily than previously assumed (McCord, 2013, Ma and Von Hippel, 2001). However, in recent times, there have been significant technological advances in low enrichment uranium (LEU) fuel systems and efforts made to improve LEU fuel technology in major universities and R\&D departments of leading nuclear laboratories (Alam, 2018). Therefore, in light of the proliferation concerns, there is a strong motivation to examine the design of marine reactor cores with the low-enriched uranium (LEU) fuel candidates.

There are several engineering challenges unique to civil marine reactors (Ragheb, 2012). Civil marine reactors must additionally be capable of operating with long refueling intervals and low fissile loadings (Hirdaris et al., 2014), which makes it fundamentally different from land-based nuclear plant system. In previous studies (Alam, 2018, Alam et al., 2019) we have examined the feasibility of micro-heterogeneous $\mathrm{ThO}_{2}-\mathrm{UO}_{2}$ duplex fuel and all- $\mathrm{UO}_{2}$ fuel for civil marine propulsion. We sought to design $333 \mathrm{MW}$ thermal power cores that will operate with long refueling intervals of (at least) 15 effective-full-power-years (EFPY). We focus on PWR technology since this is the most common reactor in the world today, with a proven record of maritime operation. PWRs are robust and proven reactors for aircraft carrier and submarine propulsion. Therefore, a PWR type small modular reactor (SMR) is considered in this study. In addition, for reasons of operational simplicity, there is no soluble boron used in naval reactors. The elimination of soluble boron offers several advantages for reactor cores. Most of these advantages are realized through significant core simplification (removal of pipes, pumping, and purification systems), space saving, the removal of the corrosive effects of soluble boron over the long core life, and from improved safety effects, improvement of the moderator temperature coefficient and elimination of an entire class of boron dilution accidents (Kim et al., 1998). Additionally, there is concern that if a ship relying on soluble boron for reactivity control were to sink, the dilution of the coolant with seawater could cause a criticality accident (Kusunoki et al., 2000).

In this study, we seek to optimize the two-dimensional lattice geometry of a 333 MWth SBF marine PWR, with an emphasis on the initial reactivity, achievable discharge burnup and conversion ratio, using $18 \%{ }^{235} \mathrm{U}$ enriched micro-heterogeneous $\mathrm{ThO}_{2}-\mathrm{UO}_{2}$ duplex fuel and $15 \%{ }^{235} \mathrm{U}$ enriched homogeneously mixed all- $\mathrm{UO}_{2}$ fuel. One way to achieve higher burnup/longer core life is to alter the neutron spectrum by changing the hydrogen-to-heavymetal ratio (H/HM), thus increasing the conversion of fertile isotopes in the fuel (Otto, 2013, $\mathrm{Xu}, 2003$, Alam et al., 2016). We have considered two types of coolant: $\mathrm{H}_{2} \mathrm{O}$ and a mixture of $80 \% \mathrm{D}_{2} \mathrm{O}+20 \% \mathrm{H}_{2} \mathrm{O}$. To date, mixing light and heavy $\mathrm{D}_{2} \mathrm{O}$ waters as a "mixed coolant" isn't practically employed (Nagy et al., 2014), although some proposed reactor designs, such as Spectral Shift Control Reactor (SSCR) (Engelder, 1961) and the Mixed Moderator PWR (MPWR) (Tochihara et al., 1998) considered this technique. In addition, for the $\mathrm{H}_{2} \mathrm{O}$ coolant, important contributions are made by an MIT study (Xu, 2003), where optimization of the PWR lattice is performed for a range of $\mathrm{H} / \mathrm{HM}$. This study explored how many different independent variables affect discharge burnup and what types of $\mathrm{H} / \mathrm{HM}$ are most effective for maximizing burnup. However, this analysis assumed licensing limits of $5 \%$ enrichment with soluble boron system. 
There is a significant gap in assessing the effect of neutron spectrum variation over burnup, especially for SBF, SMR cores (Alam, 2018, Otto, 2013, Ippolito, 1990). Therefore, the main objective of this parametric neutronic study is to observe the effects of varying the neutron spectrum under different degrees of moderation in order to maximize the attainable discharge burnup (thereby improving uranium utilisation) while maintaining a negative moderator temperature coefficient (MTC). It is important to address that since the scope of this paper is limited to "parametric neutronic analyses", the safety issues (thermal-hydraulics, fuel performance) are out of the scope of this paper.

\section{Design methods}

\subsection{Reference subassembly sizing}

Our subassembly sizing calculations use a $13 \times 13$ assembly design. For purposes of comparison, we began by considering a standard Westinghouse 4-loop PWR core, which has a fueled core area of $8.9 \mathrm{~m}^{2}$ and uses 193 assemblies with 264 pins in a $17 \times 17$ array (Winters, 2004). We found that the marine reactor requires a fueled core area of $3 \mathrm{~m}^{2}$, a $67 \%$ reduction in area (Alam, 2018, Alam et al., 2015, Otto, 2013). If 112 assemblies with a $13 \times 13$ pin array are used, we achieve this size reduction while reducing the freedom for subassembly design and core design equally (a $42 \%$ reduction in pins per assembly and a $42 \%$ reduction in assemblies per core). Fortuitously, 112 is a 'magic number' of squares that can be formed into the approximate shape of a circle (Fig. 1b). Thus, we begin with 112 assemblies with a $13 \times 13$ arrangement. In a Westinghouse $17 \times 17$ assembly, there are 24 control pins and one instrument tube ( $8.7 \%$ of pin locations). We maintain a similar ratio in our design, while preserving octant symmetry to help reduce power peaking, so we have 16 control pins $(9.5 \%$ of pin locations) and 153 fueled pins.

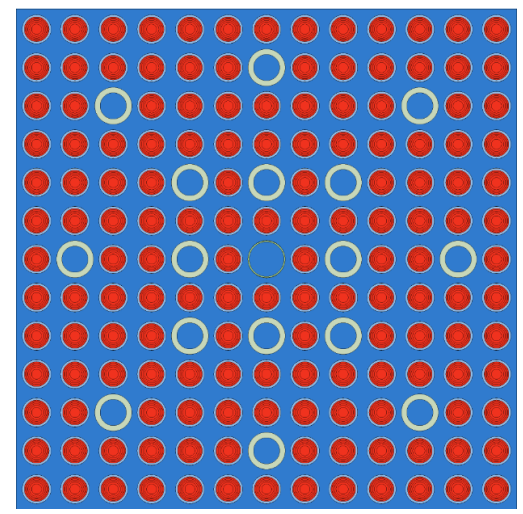

(a)

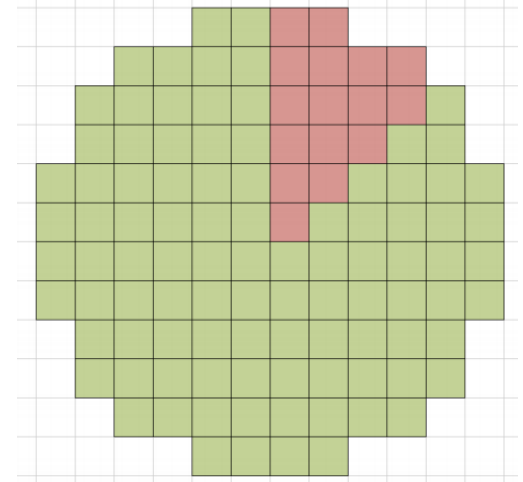

(b)

Fig. 1. Subassembly sizing: (a) $13 \times 13$ assembly geometry layout; (b) Schematic of a 112-assembly core, with one octant highlighted. 


\footnotetext{
${ }^{1}$ We use the term 'duplex' to refer to the micro-heterogeneous $\mathrm{ThO}_{2}-\mathrm{UO}_{2}$ duplex fuel throughout this paper.
}

The subassembly design analysis employed the WIMS-10 lattice physics code using nuclear data from the JEF 2.2 database available from the IAEA (Newton et al., 2008). For each burnup step, WIMS completes a 172-group 'fine' solution to the transport equation in a smeared geometry. It then refines this solution using a few-group calculation in a precise geometry. In this study, we used a 6 energy group structure, as shown in Table 1 . It is important to address the calculation route for WIMS. In our study, WIMS module HEAD sets up cross-sections in library groups and PRES/CACTUS/RES sequence does a subgroup calculation of resonance shielding, where PRES sets up subgroup cross-sections at the fuel temperature, CACTUS calculates the subgroup fluxes by Method of Characteristics (MoC) and RES completes the subgroup calculation of resonance shielding. Multicell collision probability equations is solved by PERSEUS/PIP sequence. PERSEUS calculates multicell collision probabilities for the full problem in the geometry and PIP calculates neutron spectra for each material. The condensed cross-sections and flux spectrum calculated by COND module. BURNUP module carries out depletion of fuel at specified rating and timestep.

\begin{tabular}{|l|c|c|c|c|c|c|}
\hline Group & 1 & 2 & 3 & 4 & 5 & 6 \\
\hline Upper fine group & 1 & 23 & 46 & 93 & 136 & 153 \\
Lower fine group & 22 & 45 & 92 & 135 & 152 & 172 \\
Upper (eV) & $19.64 \times 10^{6}$ & $820.85 \times 10^{3}$ & $9.12 \times 10^{3}$ & 4.00 & $625 \times 10^{-3}$ & $140 \times 10^{-3}$ \\
Lower (eV) & $820.85 \times 10^{3}$ & $9.12 \times 10^{3}$ & 4.00 & $625 \times 10^{-3}$ & $140 \times 10^{-3}$ & $110 \times 10^{-6}$ \\
\hline
\end{tabular}

Table 1. 6-group WIMS energy structure.

\subsection{Fuel selection}

There have been several past studies of homogeneously mixed $\mathrm{Th} / \mathrm{UO}_{2}$ fuel (Galperin et al., 2002) and heterogeneous seed-blanket arrangements (Kazimi et al., 1999, Todosow et al., 2005, Clayton, 1993). Homogeneously mixed $\mathrm{Th} / \mathrm{UO}_{2}$ fuel only yields promising performance in a single-batch core when the ${ }^{235} \mathrm{U}$ enrichment exceeds $20 \%$ (Galperin et al., 2002, Otto, 2013). Previous studies have indicated that thorium's advantages are best realized in micro-heterogeneous and heterogeneous geometries (MacDonald and Lee, 2004), but heterogeneous seed-blanket arrangements rely on being able to remove the seed region and replace it mid-life with fresh fuel (Kazimi et al., 1999, Todosow et al., 2005, Clayton, 1993), which is not compatible with single-batch operation. In contrast, the ability of duplex fuel to exploit the potential benefits of thorium in the context of a single-batch, low enriched uranium, SBF, long-life, small modular reactor (SMR) core is yet to be fully explored (Zhao, 2001, MacDonald and Lee, 2004). Therefore, in this study we evaluate the performance of micro-heterogeneous $\mathrm{ThO}_{2}-\mathrm{UO}_{2}$ duplex fuel ${ }^{1}$, loaded in a single-batch strategy. To provide a basis for comparison we also evaluate the performance of homogeneously mixed all- $\mathrm{UO}_{2}$ fuel. 


\subsection{Design of fissile loading}

In $\mathrm{ThO}_{2}-\mathrm{UO}_{2}$ duplex fuel, the $\mathrm{UO}_{2}$ and $\mathrm{ThO}_{2}$ components are not blended together (as in homogeneous fuel) but are discretely interspersed on small distance scales (Alam et al., 2019, Shwageraus et al., 2004, Alam et al., 2018c,d). In our case, an individual fuel pin is composed of a $\mathrm{UO}_{2}$ centre surrounded by an annulus of pure $\mathrm{ThO}_{2}$, as shown in Fig. 2.

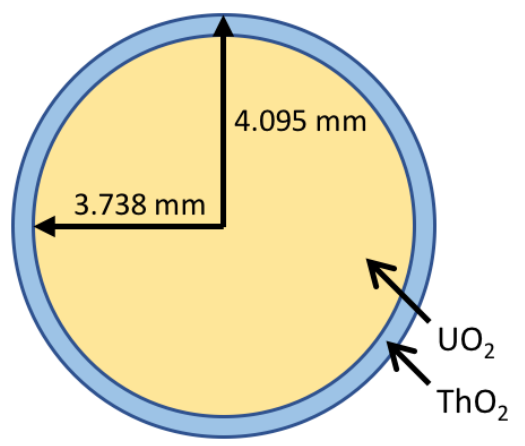

Fig. 2. Configuration of the micro-heterogeneous duplex $\mathrm{ThO}_{2}-\mathrm{UO}_{2}$ fuel.

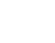
GW (X

\section{com} In conventional PWR reactor, $4 \%$ leakage is considered while considering 2D lattice-level calculations (Alam, 2018). We have estimated from our core sizing analyses that considering our marine propulsion SMR core (Power $=333$ MWth, Volume $=5.3 \mathrm{~m}^{3}$ ), leakage of $7.5 \%$ is considered conservative. This leakage has been checked with 3D whole-core nodal diffusion code PANTHER (Hutt, 1992). In the assembly level analysis for fresh fuel in WIMS (which assumes an infinitely-large core), discharge burnup is $95 \mathrm{GWd}$ /tonne considering $7.5 \%$ leakage, while whole-core exhibits the average burnup of $97 \mathrm{GWd} /$ tonne, which proves that $7.5 \%$ leakage is conservative for our SMR core design. The discharge burnup is therefore estimated from the point on the assembly burnup curve where the infinite multiplication factor, $k_{\infty}$, is 1.075 .

The fissile loadings of the duplex and $\mathrm{UO}_{2}$ fuels were determined from enrichment sensitivity studies, seeking values that keep the core critical for a burnup of $\sim 95 \mathrm{GWd} /$ tonne. It is clear from Figs. 3a and 3b that, in order to achieve the target discharge burnup, initial enrichments of $15 \%$ and $18 \%{ }^{235} \mathrm{U}$ are required for the $\mathrm{UO}_{2}$ and duplex fuels, respectively. The duplex fuel requires higher enrichment than the all- $\mathrm{UO}_{2}$ fuel due, in part, to the lower 


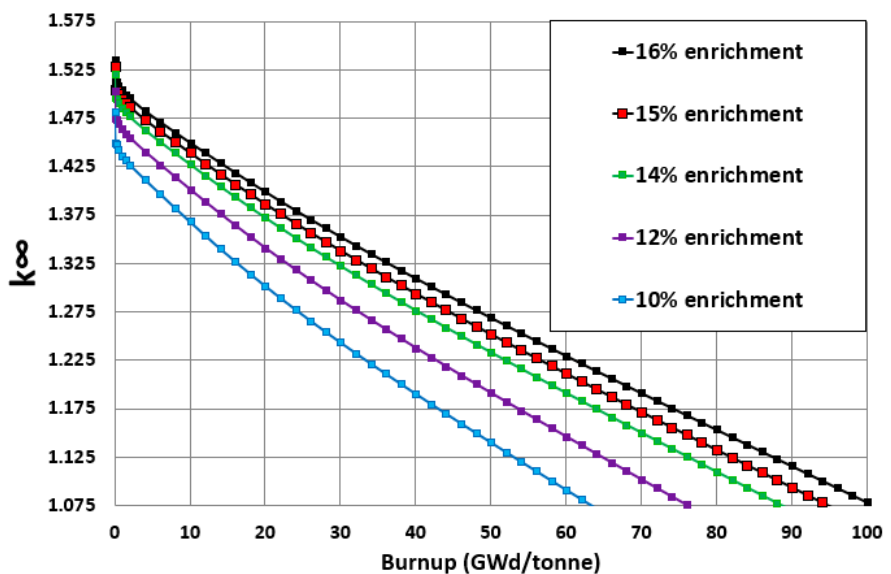

(a)

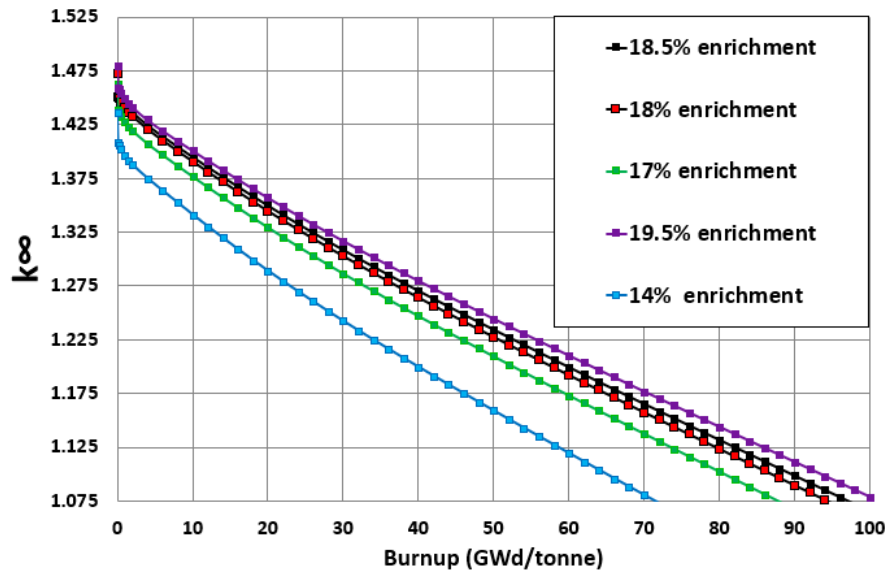

(b)

Fig. 3. Fuel depletion calculations for various fissile loadings: (a) $\mathrm{UO}_{2}$ fuel; (b) Duplex fuel. 
volume of $\mathrm{UO}_{2}$ in the fuel and, in part, to the higher thermal absorption cross-section of the fertile ${ }^{232} \mathrm{Th}$.

Lattice physics calculations for the assemblies were performed in previous studies (Almutairi et al., 2018, Alam et al., 2018b,a) using the deterministic transport code WIMS, the Monte Carlo (MC) code Serpent (Leppänen and Pusa, 2009) and the hybrid MC code MONK (Long et al., 2015). For both candidate fuels, excellent agreement ( 100-350 pcm) was observed between the codes, giving reassurance that WIMS can be used to provide reliable lattice physics results for SBF marine propulsion cores at much reduced computational cost compared to the MC code Serpent and hybrid MC code MONK.

\subsection{Coolant molecular ratios}

Next, we use mixtures of light and heavy water at molecular ratios ranging from $0 \%$ to $100 \% \mathrm{D}_{2} \mathrm{O}$ with both candidate fuels. Figs. $4 \mathrm{a}$ and $4 \mathrm{~b}$ show that both fuels achieve the highest discharge burnup with the $80 \% \mathrm{D}_{2} \mathrm{O}+20 \% \mathrm{H}_{2} \mathrm{O}$ mixed coolant. Neutron capture in $\mathrm{D}_{2} \mathrm{O}-\mathrm{H}_{2} \mathrm{O}$ dominates when it is more than $80 \% \mathrm{D}_{2} \mathrm{O}$ due to the substantial degradation in the thermal neutron utilization arising from the reduced presence of hydrogen atoms.n This necessarily provides the highest uranium utilization, making this coolant composition the natural choice to take forward in this study. As expected, since deuterium is not as efficient a neutron moderator as hydrogen, the neutron spectrum was found to be increasingly hardened and the resonance flux relatively higher as the $\mathrm{D}_{2} \mathrm{O}$ percentage in the moderator increased.

The reference design parameters of the proposed marine core are shown in Table 2 (Alam, 2018).

\begin{tabular}{|l|c|}
\hline Parameter & Value \\
\hline Thermal power (MWth) & 333.33 \\
Minimum desired lifetime (years) & 15 \\
Assembly size & $13 \times 13$ \\
Control rods per assembly & 16 \\
Pin pitch (mm) & 12.65 \\
Fuel pellet diameter $(\mathrm{mm})$ & 8.19 \\
Cladding thickness $(\mathrm{mm})$ & 0.605 \\
Gap thickness $(\mathrm{mm})$ & 0.0498 \\
Number of assemblies & 112 \\
Fuel height $(\mathrm{m})$ & 1.79 \\
Core diameter $(\mathrm{m})$ & 1.97 \\
Pitch/diameter ratio & 1.33 \\
Hydrogen-to-heavy metal $(\mathrm{H} / \mathrm{HM})$ ratio & 3.99 \\
Assembly side length $(\mathrm{cm})$ & 16.45 \\
Assembly area $\left(\mathrm{m}^{2}\right)$ & 0.03 \\
Power density $\left(\mathrm{MW}^{2} \mathrm{~m}^{3}\right)$ & 63 \\
Average linear rating $(\mathrm{kW} / \mathrm{m})$ & 10 \\
\hline
\end{tabular}

Table 2. Reference design parameters of proposed marine core. 


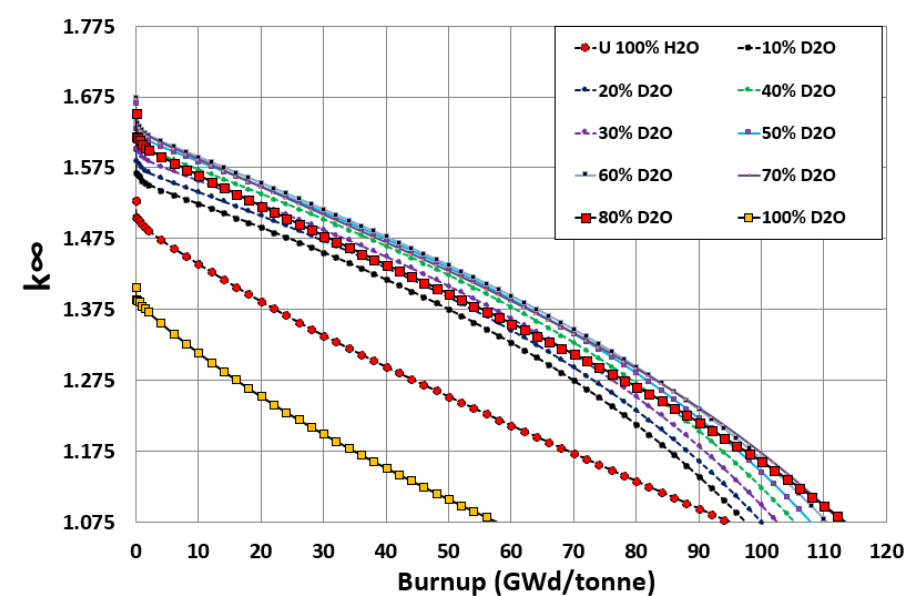

(a)

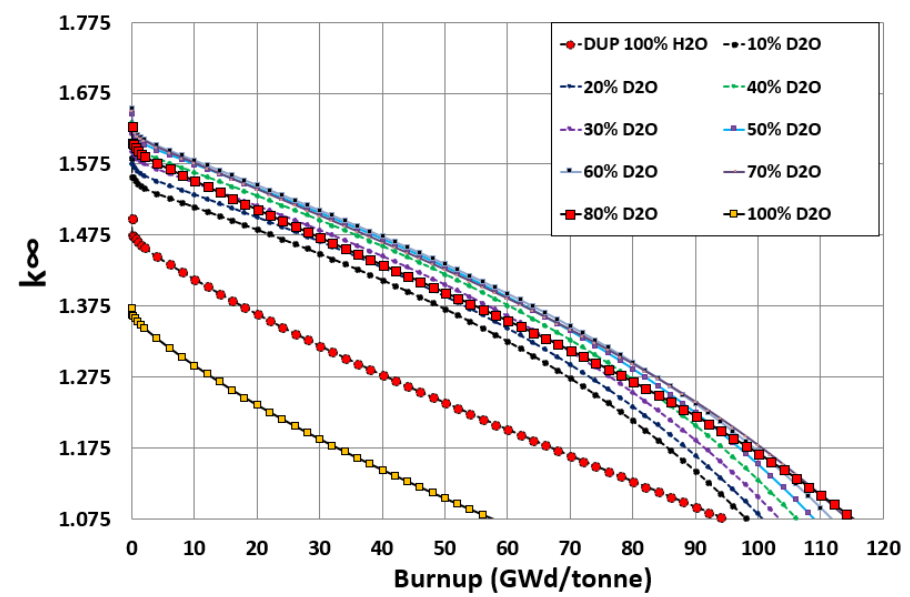

(b)

Fig. 4. Fuel depletion calculations for varying molecular ratios of light and heavy water: (a) $15 \%{ }^{235} \mathrm{U}$ enriched $\mathrm{UO}_{2}$ fuel; (b) $18 \%{ }^{235} \mathrm{U}$ enriched duplex fuel. 


\section{Lattice geometry optimization and moderation effects}

The main objective of this parametric study is to observe the effects of varying the neutron spectrum under different degrees of moderation in order to maximize the attainable discharge burnup and secure improved uranium utilization while maintaining a negative MTC. Since the achievable burnup is dependent on the hydrogen-to-heavy-metal ratio $(\mathrm{H} / \mathrm{HM})$ for $\mathrm{H}_{2} \mathrm{O}$ coolant, and on the deuterium-hydrogen/heavy-metal ratio ( $\mathrm{DH} / \mathrm{HM})$ for mixed $\mathrm{D}_{2} \mathrm{O}-\mathrm{H}_{2} \mathrm{O}$ coolant, we optimize these ratios by changing: (1) the fuel rod diameter; (2) the pin pitch; and (3) the coolant density. Together, these parameters determine the reactor's H/HM and $\mathrm{DH} / \mathrm{HM}$ ratios, and hence have a crucial effect on the neutron energy spectrum.

Our strategy for this study of moderation effects is the following: by varying the $\mathrm{H} / \mathrm{HM}$ and $\mathrm{DH} / \mathrm{HM}$ ratio in a core, we can find the most suitable operating range with respect to achievable discharge burnup for a given initial enrichment for the candidate fuels. Optimizing moderation to achieve long core life requires a balance to be struck between three main factors (Alam, 2018):

(a) Early in life, it is desirable to encourage a higher neutron capture rate in the fertile components of the fuel, suppressing initial reactivity and enhancing the breeding of new fissile material.

(b) Late in life, it is necessary to reduce captures in the fertile components of the fuel so as to increase the core reactivity, which helps in preventing the core from losing criticality.

(c) And throughout all stages of life, it is necessary to maintain a sufficiently negative MTC to ensure stable operation.

In this study, we have defined the following:

1. The fast region to correspond to a $\mathrm{H} / \mathrm{HM}$ or $\mathrm{DH} / \mathrm{HM}<0.50$, the epithermal region to $\mathrm{H} / \mathrm{HM}$ or $\mathrm{DH} / \mathrm{HM}$ between 0.50 and 2.88 , and the thermal region to $\mathrm{H} / \mathrm{HM}$ or $\mathrm{DH} / \mathrm{HM}$ $>2.88$ (Xu and Driscoll, 1997, Alam, 2018).

2. We refer to the region below the optimal (point of highest discharge burnup) $\mathrm{H} / \mathrm{HM}$ or $\mathrm{DH} / \mathrm{HM}$ as 'under-moderated' and the region above the optimum as 'over-moderated'.

3. The reference values of pin pitch $=12.65 \mathrm{~mm}$, fuel pin diameter $=9.50 \mathrm{~mm}$, coolant density $=0.707 \mathrm{~g} / \mathrm{cm}^{3}$ (for $\mathrm{H}_{2} \mathrm{O}$ ) and $1.0832 \mathrm{~g} / \mathrm{cm}^{3}$ (for $80 \% \mathrm{D}_{2} \mathrm{O}+20 \% \mathrm{H}_{2} \mathrm{O}$ ).

We use ' $\mathrm{D}_{2} \mathrm{O}$ ' as a short-hand label for the $80 \% \mathrm{D}_{2} \mathrm{O}+20 \% \mathrm{H}_{2} \mathrm{O}$ coolant $^{2}$.

\subsection{Initial reactivity}

The focus here is on the beginning-of-life (BOL) $k_{\infty}$ of poison-free fuel lattices at hot full power and xenon-free conditions. We have investigated BOL $k_{\infty}$ by varying the coolant density, fuel pin diameter and pin pitch over wide ranges with other parameters held constant. These resulting plots provide information on several points of interest.

Fig. 5a shows that an increase in $\mathrm{H} / \mathrm{HM}$ leads to a higher BOL $k_{\infty}$ for both the duplex and all- $\mathrm{UO}_{2}$ fuels up to some value of $\mathrm{H} / \mathrm{HM}$. Due to the increased presence of hydrogen

\footnotetext{
${ }^{2} 80 \% \mathrm{D}_{2} \mathrm{O}+20 \% \mathrm{H}_{2} \mathrm{O}$ coolant is referred to interchangeably as 'mixed coolant' and ' $\mathrm{D}_{2} \mathrm{O}$ '.
} 
atoms, neutrons are better thermalized (Fig. $5 \mathrm{~b}$ ) up to $\mathrm{H} / \mathrm{HM} \approx 15$ for $\mathrm{H}_{2} \mathrm{O}$ coolant. $k_{\infty}$ peaks at this $\mathrm{H} / \mathrm{HM}$ value and tends to decrease thereafter. In the over-moderated region, $k_{\infty}$ decreases as $\mathrm{H} / \mathrm{HM}$ increases since the large capture cross-section of water begins to dominate the effect of improved neutron thermalization (Xu and Driscoll, 1997). It should be noted that our reference marine PWR lattice has H/HM and DH/HM values of 3.99 and 5.0 , respectively and therefore is not optimal if trying to maximize BOL $k_{\infty}$.

Figs. $6 \mathrm{a}$ and $6 \mathrm{~b}$ show that the variation of $\mathrm{BOL} k_{\infty}$ for the candidate fuels is similar with the $\mathrm{D}_{2} \mathrm{O}-\mathrm{H}_{2} \mathrm{O}$ coolant for similar reasons. $k_{\infty}$ peaks at around $\mathrm{DH} / \mathrm{HM} \approx 10$. Neutron absorption in mixed $\mathrm{D}_{2} \mathrm{O}-\mathrm{H}_{2} \mathrm{O}$ coolant begins to play a dominant role at a lower value of $\mathrm{DH} / \mathrm{HM}$ (compared to $\mathrm{H} / \mathrm{HM}$ for the $\mathrm{H}_{2} \mathrm{O}$ coolant) due to the substantial degradation in the thermal neutron utilization arising from the reduced presence of hydrogen atoms.

Figs. $5 \mathrm{a}$ and $6 \mathrm{a}$ show that the peak value of $k_{\infty}$ is lower for the duplex fuel than the all- $\mathrm{UO}_{2}$ fuel for both coolants. This is because ${ }^{232} \mathrm{Th}$ has a higher absorption cross-section than ${ }^{238} \mathrm{U}$. The peak $k_{\infty}$ of both candidate fuels with the $\mathrm{D}_{2} \mathrm{O}-\mathrm{H}_{2} \mathrm{O}$ coolant is $\sim 2 \%$ higher than with the $\mathrm{H}_{2} \mathrm{O}$ coolant in the under-moderated region, due to the presence of large volumes $(80 \%)$ of $\mathrm{D}_{2} \mathrm{O}$ and its small neutron capture cross-section compared to $\mathrm{H}_{2} \mathrm{O}$ coolant.

Fig. 7 shows the BOL normalized neutron flux ratio (the ratio of the flux in the mixed coolant to that in the $\mathrm{H}_{2} \mathrm{O}$ coolant) for $\mathrm{UO}_{2}$ fuel. It suggests that the mixed coolant yields a softer spectrum than the $\mathrm{H}_{2} \mathrm{O}$ coolant. The ratio in the thermal range is $~ 1.65-1.70$, meaning that flux values in the thermal range are $\sim 65-70 \%$ softer for the mixed coolant. Thus, the peak $k_{\infty}$ values are higher for the mixed coolant due to better neutron thermalization compared to the $\mathrm{H}_{2} \mathrm{O}$ coolant.

Things are different in the over-moderated region, where neutron capture in the mixed coolant dominates capture in $\mathrm{H}_{2} \mathrm{O}$. Fig. 8 show that $\mathrm{BOL} k_{\infty}$ values for the mixed coolant become lower than corresponding values for the $\mathrm{H}_{2} \mathrm{O}$ coolant towards the upper end of this region.

The sensitivity of BOL $k_{\infty}$ to varying fuel pin diameter (over the range 4.79-9.50 mm), while keeping the pin pitch and coolant density constant (at reference values), was investigated. Fig. 9 shows the peak BOL $k_{\infty}$ values of the $\mathrm{UO}_{2}$ and duplex fuels with $\mathrm{H}_{2} \mathrm{O}$ coolant occur at $\mathrm{H} / \mathrm{HM}=14$ and 16 , respectively. Due to the presence of a strong thermal absorber $\left({ }^{232} \mathrm{Th}\right)$, the peak $k_{\infty}$ of duplex fuel is $4 \%$ less than for the $\mathrm{UO}_{2}$ fuel, which is beneficial from the perspective of reactivity control.

In contrast, it can be seen for the mixed coolant that peak BOL $k_{\infty}$ values are reached for $\mathrm{DH} / \mathrm{HM} \approx 8$. At high $\mathrm{H} / \mathrm{HM}$ and $\mathrm{DH} / \mathrm{HM}$ ratios, $\mathrm{BOL} k_{\infty}$ values for the $\mathrm{H}_{2} \mathrm{O}$ coolant are higher compared to those for the $\mathrm{D}_{2} \mathrm{O}$ coolant for both the candidate fuels. This is due to the dominance of the elastic scattering cross-section of hydrogen (which is 5 times greater than that of deuterium in the slowing-down energy range).

Finally, we increased the pin pitch (over the range 9.51-23.08 mm) while keeping the fuel diameter and coolant density constant at reference values. Fig. 10 shows that the peak BOL $k_{\infty}$ of the all- $-\mathrm{UO}_{2}$ fuel is $1.2 \%$ and $1.8 \%$ higher than that for the duplex fuel for the $\mathrm{D}_{2} \mathrm{O}$ and $\mathrm{H}_{2} \mathrm{O}$ coolants, respectively. Both candidate fuels reach peak BOL $k_{\infty}$ values at an $\mathrm{H} / \mathrm{HM}$ value of 14 and a $\mathrm{DH} / \mathrm{HM}$ value of 9 for the $\mathrm{D}_{2} \mathrm{O}$ and $\mathrm{H}_{2} \mathrm{O}$ coolants, respectively.

From a neutronics viewpoint it can be anticipated that with decreases in $\mathrm{H} / \mathrm{HM}$ or $\mathrm{DH} / \mathrm{HM}$ 


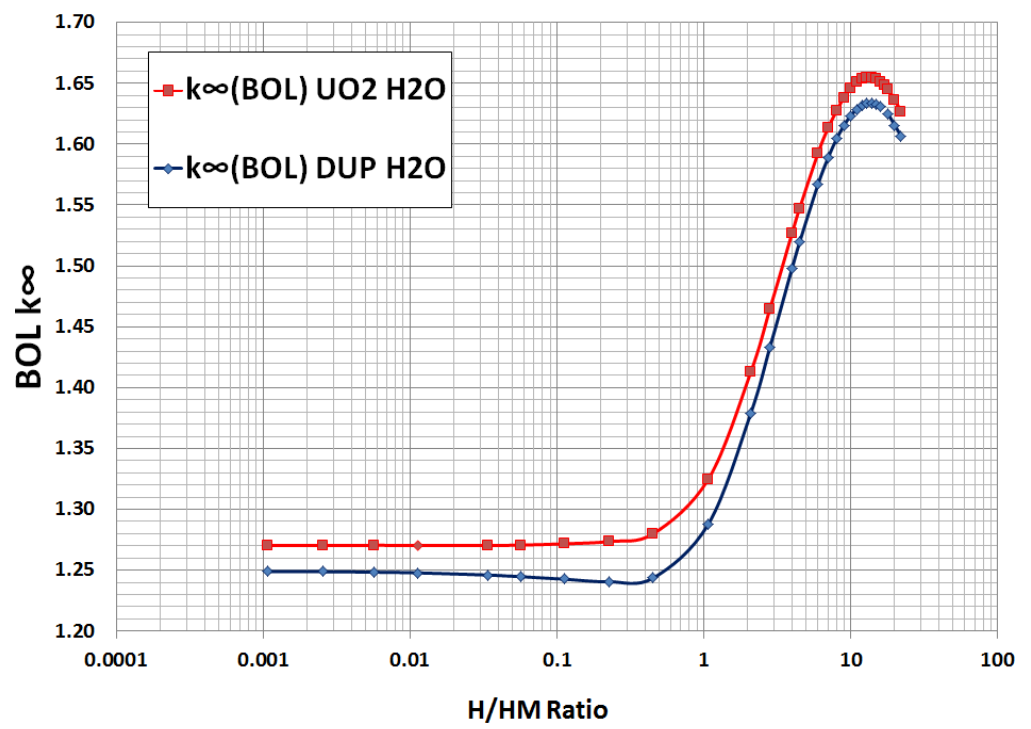

(a)

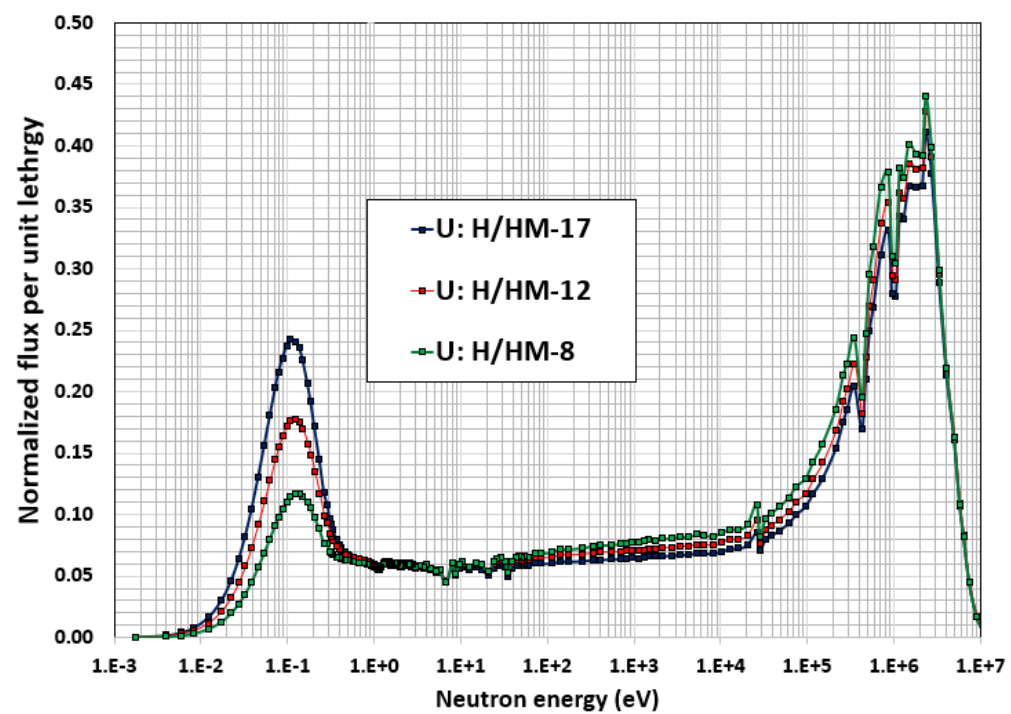

(b)

Fig. 5. (a) Initial $k_{\infty}$ as a function of $\mathrm{H} / \mathrm{HM}$ by varying coolant density. (b) Neutron spectra normalized per unit flux at BOL by varying $\mathrm{H}_{2} \mathrm{O}$ density for $\mathrm{UO}_{2}$ fuel $-\mathrm{H} / \mathrm{HM}$ values of 8,12 and 17 are shown. 


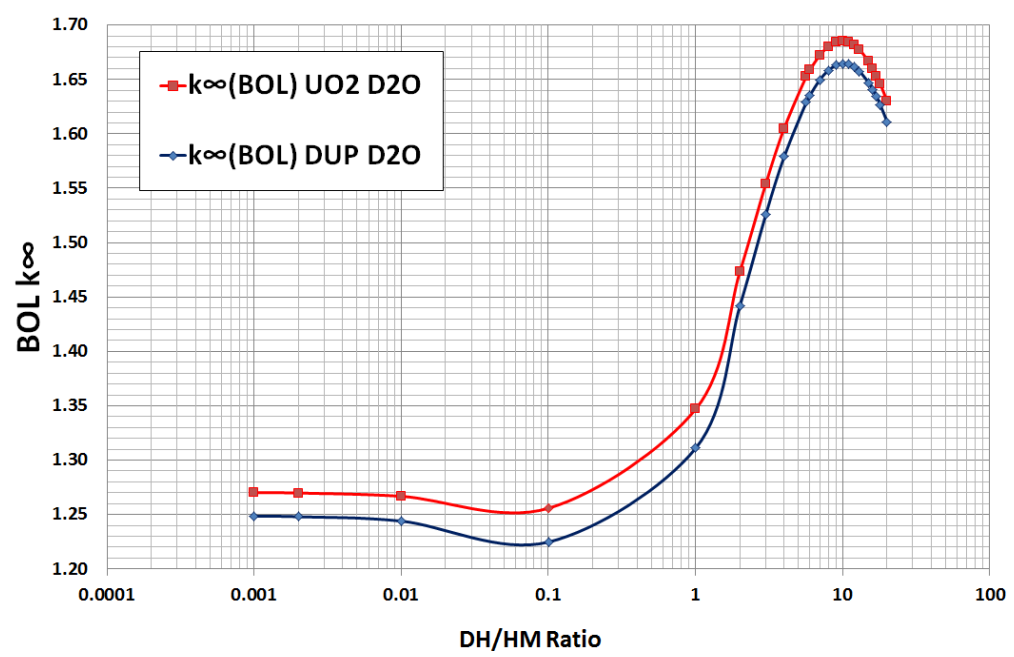

(a)

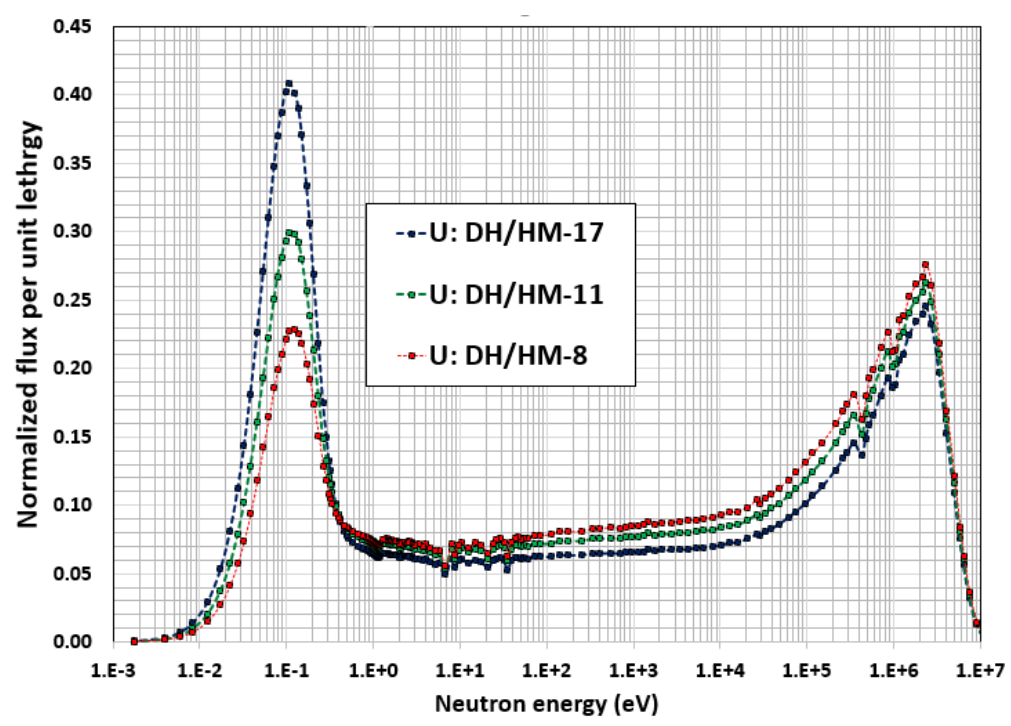

(b)

Fig. 6. (a) Initial $k_{\infty}$ as a function of $\mathrm{DH} / \mathrm{HM}$ by varying coolant density. (b) Neutron spectra normalized per unit flux at BOL by varying $\mathrm{D}_{2} \mathrm{O}-\mathrm{H}_{2} \mathrm{O}$ density for $\mathrm{UO}_{2}$ fuel $-\mathrm{DH} / \mathrm{HM}$ values of 8,11 and 17 are shown. 


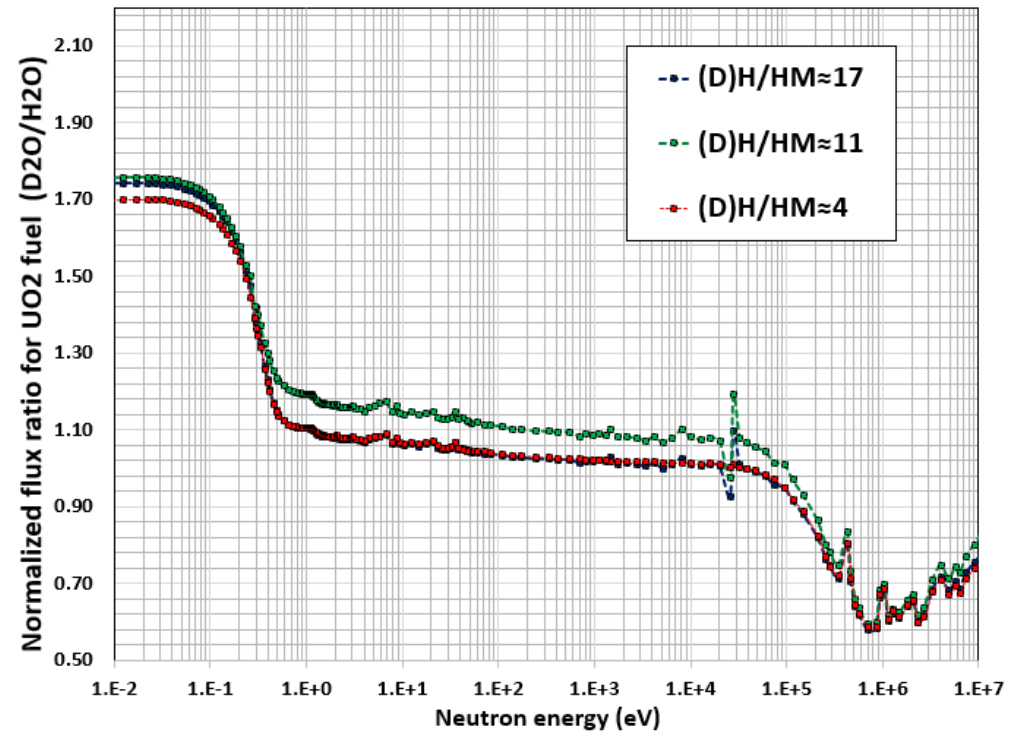

Fig. 7. Normalized neutron flux ratios $\left(\mathrm{D}_{2} \mathrm{O}-\mathrm{H}_{2} \mathrm{O}: \mathrm{H}_{2} \mathrm{O}\right.$ coolant) for $\mathrm{UO}_{2}$ fuel at $\mathrm{BOL}$.

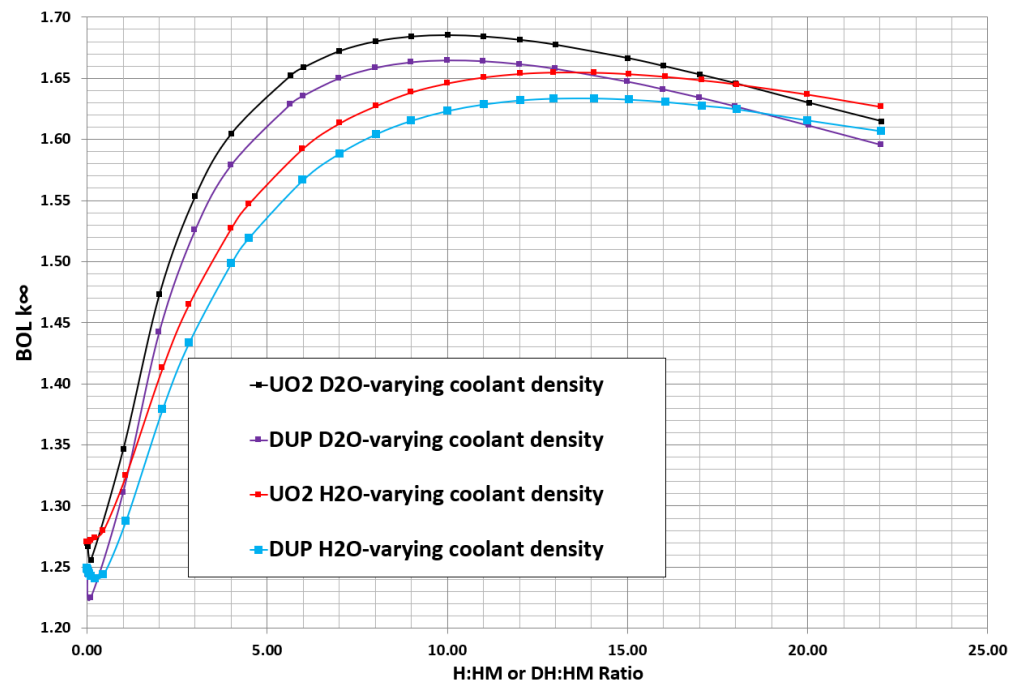

Fig. 8. BOL $k_{\infty}$ as a function of $\mathrm{H} / \mathrm{HM}$ or $\mathrm{DH} / \mathrm{HM}$ for all- $\mathrm{UO}_{2}$ and duplex fuels by varying coolant density. 


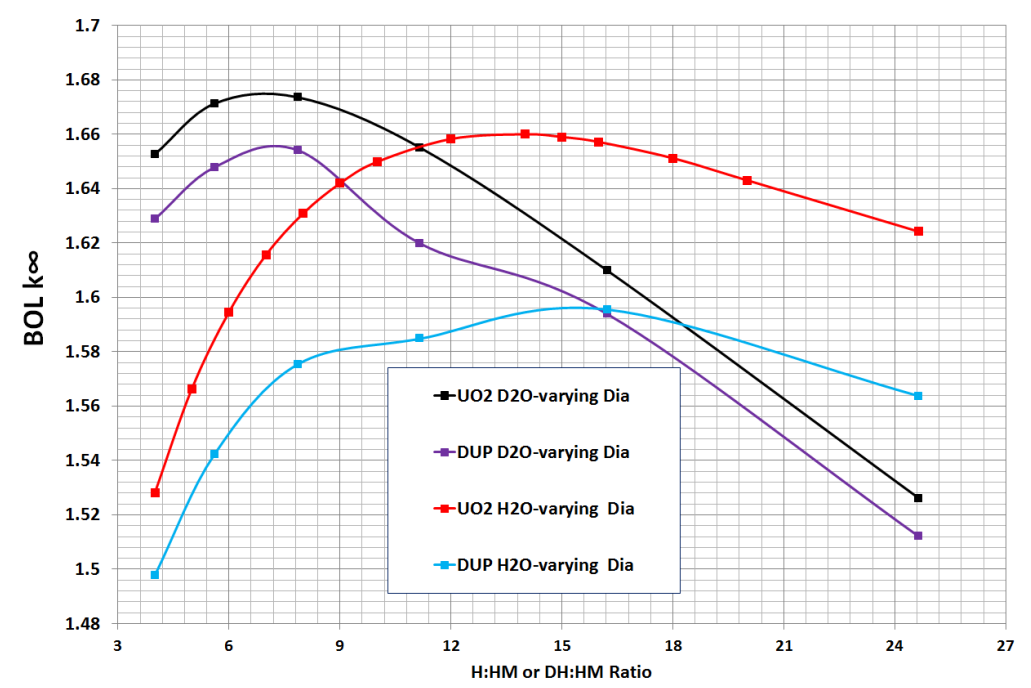

Fig. 9. BOL $k_{\infty}$ as a function of $\mathrm{H} / \mathrm{HM}$ or $\mathrm{DH} / \mathrm{HM}$ by varying fuel diameter (standard pitch).

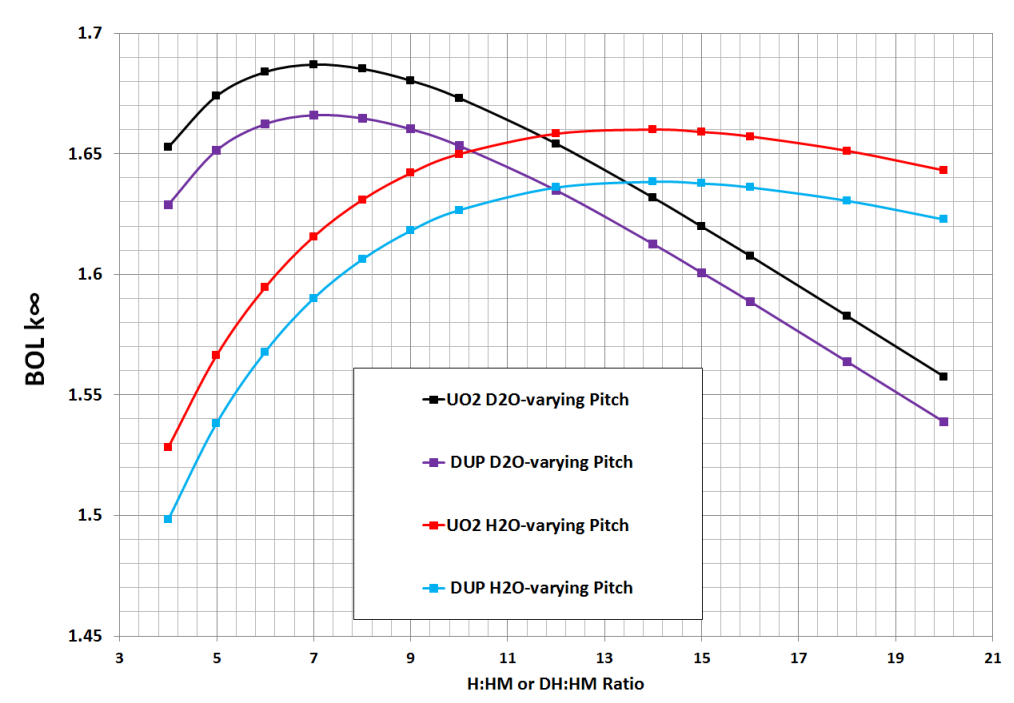

Fig. 10. BOL $k_{\infty}$ as a function of $\mathrm{H} / \mathrm{HM}$ or $\mathrm{DH} / \mathrm{HM}$ by varying pitch (standard fuel diameter). 
below the optimal ratios, the neutron migration length increases so that the lattice becomes ever more homogenized. The hardening of the neutron spectrum increases the resonance absorption in ${ }^{238} \mathrm{U}$ relative to ${ }^{235} \mathrm{U}$. Thus a monotonic decrease in $k_{\infty}$ with decreasing $\mathrm{H} / \mathrm{HM}$ and $\mathrm{DH} / \mathrm{HM}$ is observed.

Control requirements are largely determined by the initial reactivity, and this parametric study suggests that wetter lattices need more control. It can be concluded that BOL $k_{\infty}$ is higher for the all- $\mathrm{UO}_{2}$ fuel for both coolants, which will certainly exacerbate the reactivity control requirements for SBF operation. Conversely, the duplex candidate fuel will require less burnable absorber than the all- $\mathrm{UO}_{2}$ fuel for reactivity suppression. Since the $\mathrm{D}_{2} \mathrm{O}$ coolant provides higher peak BOL $k_{\infty}$ for both fuels, it will require greater poison loading for reactivity suppression, although this disadvantage may be offset by the higher achievable discharge burnup that results. Since soluble boron isn't used for reactivity control, it is required to use integral fuel burnable absorber (IFBA) burnable poison as traditional poison like gadolinia and/or erbia wasnt efficient enough (Alam, 2018, Alam et al., 2015). Therefore, a high-thickness $\mathrm{ZrB}_{2}$ IFBA poison coating is considered in order to achieve the crucial self-shielding effect, investigating coatings of $150 \mu \mathrm{m}$ (Alam, 2018). In our IFBA assembly design, $150 \mu \mathrm{m}$ adhesive coating of zirconium diboride is coated onto the outer surface of a $\mathrm{UO}_{2}$ pellet. For the duplex fuel case, IFBA layers are applied on the outer surface of the $\mathrm{ThO}_{2}$ region. In order to suppress high initial and through-life reactivity swing, we used boron $95 \%$ enriched in ${ }^{10} \mathrm{~B}$ throughout in order to increase neutronic effectiveness. In boron $95 \%$ enriched with ${ }^{10} \mathrm{~B}$, the ratio of the absorption to total cross-section $\sigma_{a} / \sigma_{t}=0.95$, and therefore boron is an approximately black absorber. When incorporated into $\mathrm{ZrB}_{2}$ (density: $6.5 \mathrm{~g} / \mathrm{cm}^{3}$ ), it has a macroscopic absorption cross-section of $\Sigma=297 \mathrm{~cm}^{-1}$, and therefore a mean free path $\lambda$ of $\sim 34 \mu \mathrm{m}$ (Otto, 2013, Alam, 2018, Alam et al., 2015). As a result, 150 $\mu \mathrm{m}$ coating has poison layer with thickness greater than $3 \lambda$ and these high-thickness poison layers can therefore intercept at least $\sim 95 \%$ of incident neutrons. In addition, the existing subassembly design has 16 guide-tubes for loading control rods and a standard 16-rod rod cluster control assembly (RCCA) of $\mathrm{B}_{4} \mathrm{C}$ is used. In our 112-assembly marine PWR core, 3 banks of control rods (A, B and $\mathrm{C}$ ) are used for power maneuvering and 3 other banks (SA, SB and SC) are used for shutdown. A total of 36 rod cluster control assemblies each of 16 rods are used. Finally, $\mathrm{B}_{4} \mathrm{C}$ control rod bank banks are used for obtaining criticality over life (Alam, 2018).

\subsection{Achievable discharge burnup}

We now examine the reactivity-limited achievable discharge burnup $\left(B_{D}\right)$ as a function of $\mathrm{H} / \mathrm{HM}$ and $\mathrm{DH} / \mathrm{HM} . B_{D}$ is defined from the burnup value on the depletion curve $\left(k_{\infty}\right.$ vs. burnup) where $k_{\infty}=1$, i.e. leakage is not considered in this analysis. The sensitivity of $B_{D}$ is observed for varying coolant density, fuel pin diameter and pin pitch. Figs. 11 and 12 show that the duplex fuel can achieve up to $\sim 2 \%$ more discharge burnup compared to the $\mathrm{UO}_{2}$ fuel for both coolants by varying fuel pin diameter (over the range $4.79 \mathrm{~mm}-9.50 \mathrm{~mm}$ ) and pin pitch (over the range 12.65-23.08 $\mathrm{mm}$ ).

In contrast, the duplex fuel can achieve $~ 7 \%$ higher discharge burnup than the $\mathrm{UO}_{2}$ fuel by varying the coolant density (over the ranges $2.0 \times 10^{-3}-3.90 \mathrm{~g} / \mathrm{cm}^{3}\left(\right.$ for $\mathrm{H}_{2} \mathrm{O}$ ) and 


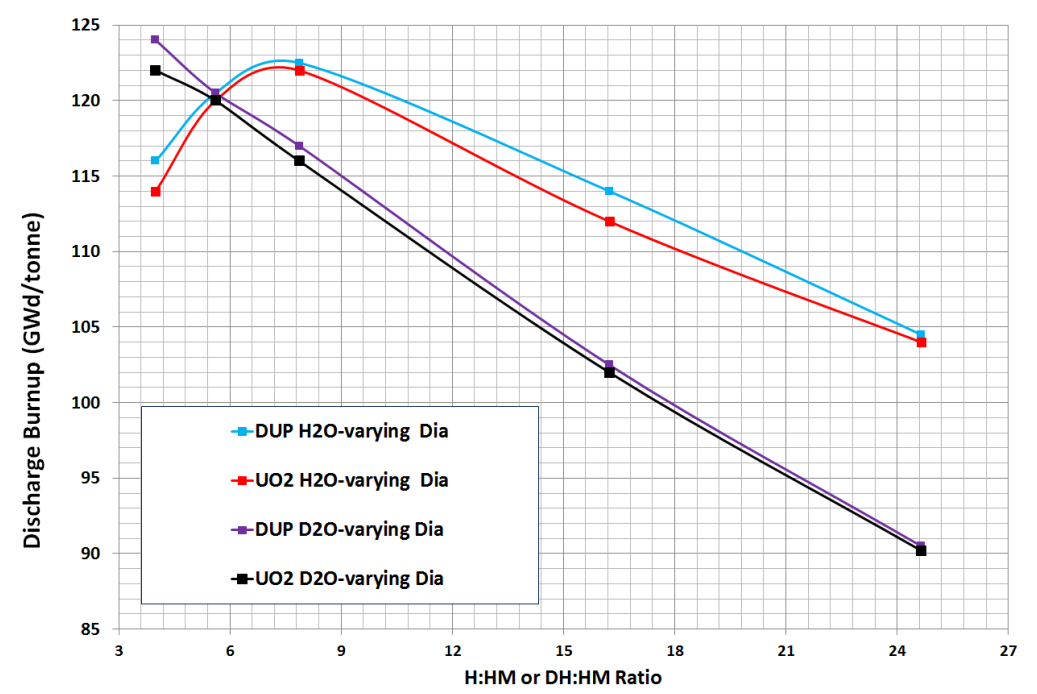

Fig. 11. $B_{D}$ as a function of $\mathrm{H} / \mathrm{HM}$ or $\mathrm{DH} / \mathrm{HM}$ by varying fuel diameter (standard pitch).

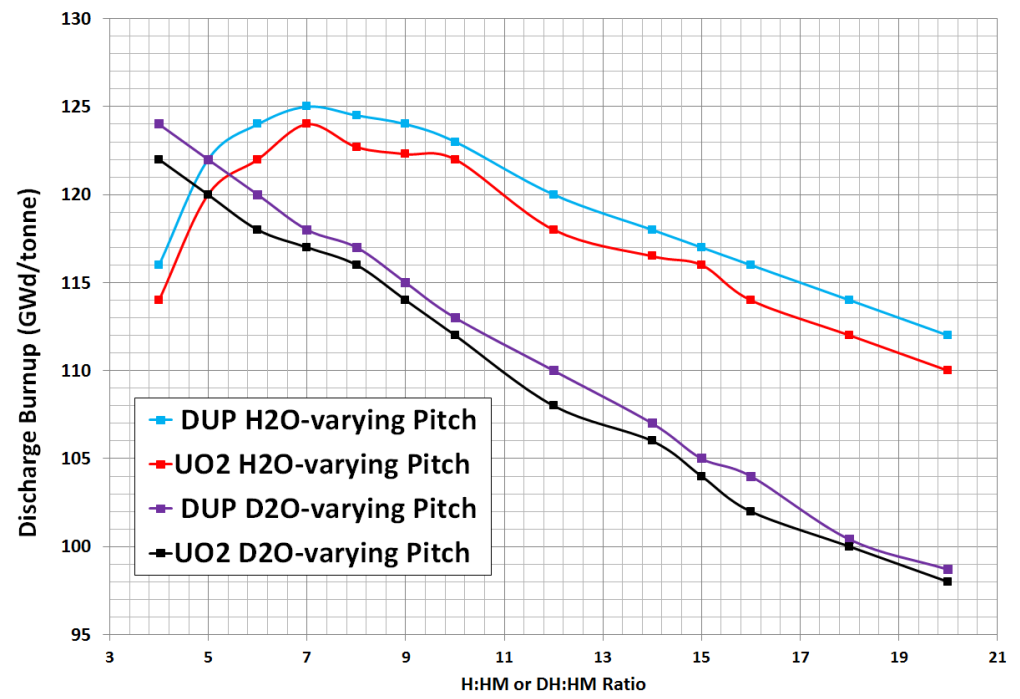

Fig. 12. $B_{D}$ as a function of $\mathrm{H} / \mathrm{HM}$ or $\mathrm{DH} / \mathrm{HM}$ by varying pitch (standard fuel diameter). 
$1.92 \times 10^{-4}-3.84 \mathrm{~g} / \mathrm{cm}^{3}$ (for the mixed coolant)), as shown in Fig. 13. This is due to the improved 'fertile-capture-to-fissile-absorption ratio' of duplex fuel (Fig. 14), which is advantageous for achieving better fissile accumulation potential and thus leads to higher discharge burnups.

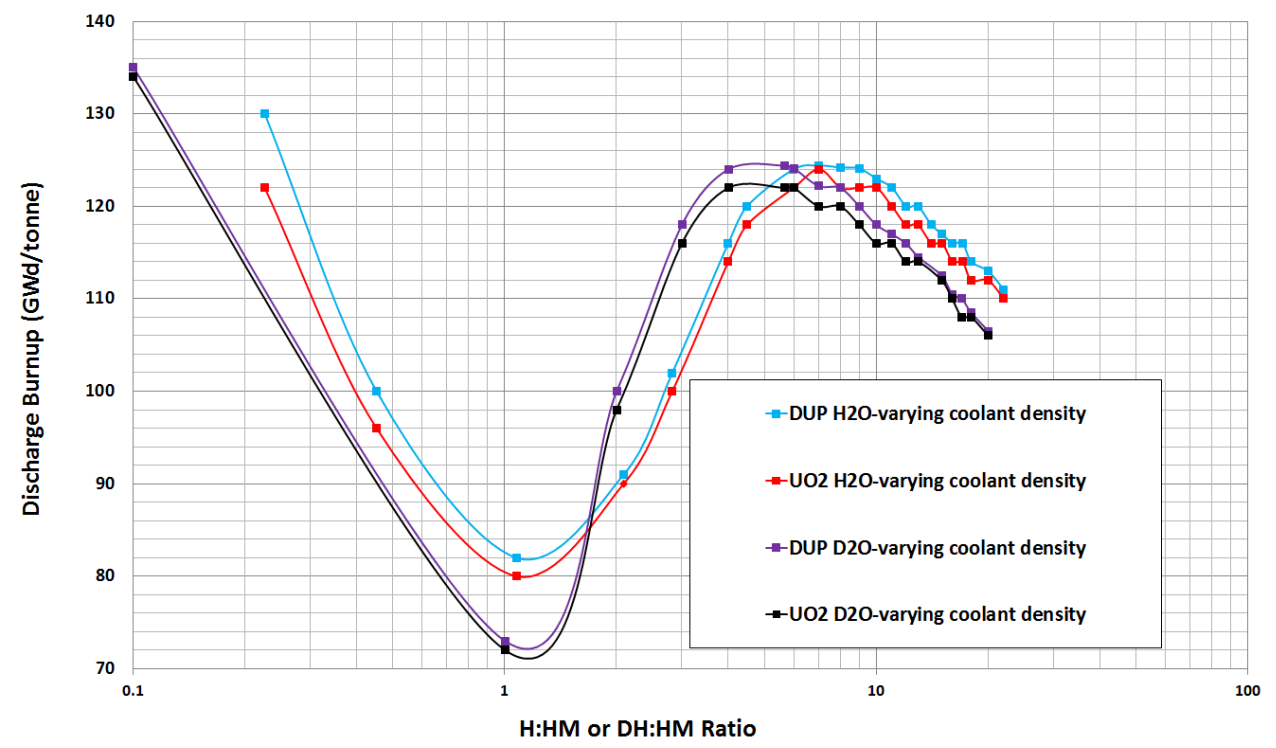

Fig. 13. $B_{D}$ as a function of $\mathrm{H} / \mathrm{HM}$ and $\mathrm{DH} / \mathrm{HM}$ ratio by varying coolant density. and $\mathrm{H} / \mathrm{HM} \approx 7\left(\mathrm{H}_{2} \mathrm{O}\right)$.

For all these lattice optimizations (varying the coolant density, fuel pin diameter and pin pitch), the duplex fuel consistently offers higher achievable discharge burnups for all moderation regimes for both coolants. It can achieve $B_{D}$ values of $125 \mathrm{GWd} /$ tonne with $\mathrm{H}_{2} \mathrm{O}(\mathrm{H} / \mathrm{HM}=7)$ and $124 \mathrm{GWd} /$ tonne with $\mathrm{D}_{2} \mathrm{O}-\mathrm{H}_{2} \mathrm{O}(\mathrm{DH} / \mathrm{HM}=4)$, respectively, which represent $\sim 7 \%$ increases in $B_{D}$ compared to a reference lattice.

Although higher discharge burnups can be achieved with a hard spectrum ((D)H/HM « 


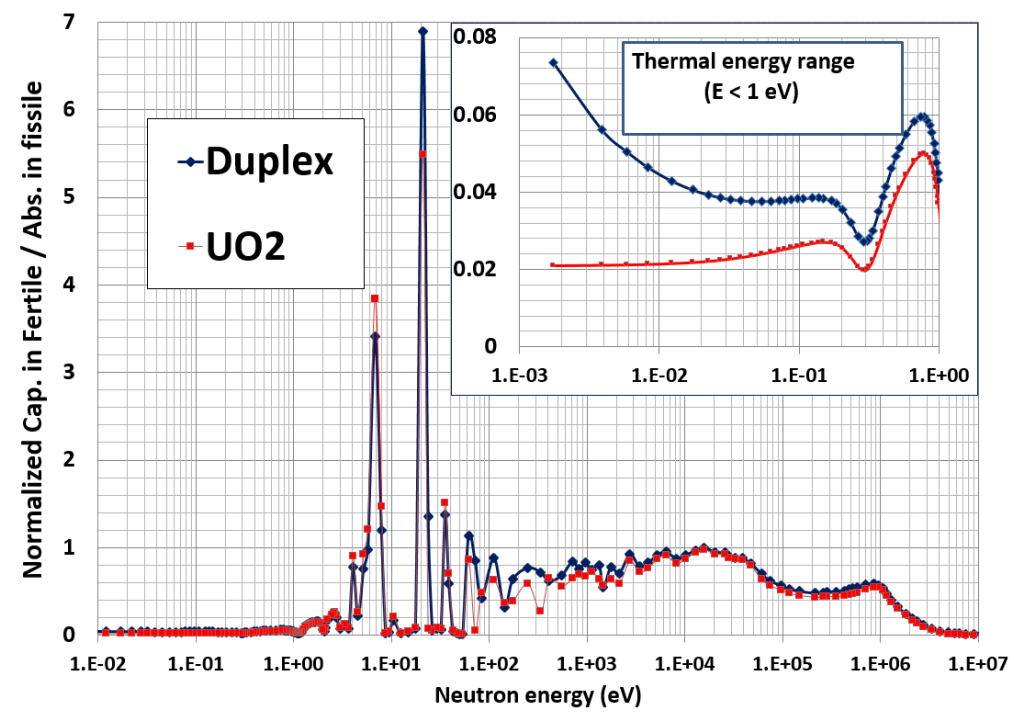

Fig. 14. Fertile-capture:fissile-absorption ratios at BOL.

1), the analysis of initial reactivity in Sect. 3.1 showed BOL $k_{\infty}$ values are significantly lower in this moderation regime.

\subsection{Conversion ratio}

The relationship between discharge burnup and initial reactivity can be explained using the concept of conversion ratio $(\mathrm{CR})$, which measures the ratio of the fuel's end-of-life (EOL) and BOL fissile content. The variation of the 'achievable discharge burnup' can be understood using the linear reactivity model (Driscoll et al., 1990). Using this model, the discharge burnup in single-batch operation is determined by the initial reactivity and the slope of the $k_{\infty}$-burnup characteristic, which is proportional to (1/CR) (Xu and Driscoll, 1997). Here, the BOL CR is calculated as a function of $(\mathrm{D}) \mathrm{H} / \mathrm{HM}$ by varying coolant densities while keeping the fuel diameter and pin pitch constant (at reference values) over the range of moderation regimes. It can be observed from Fig. 15 that overall the CR decreases as (D)H/HM increases, implying that the net fissile content declines faster with increasing moderation. By looking at the figures for initial reactivity (Figs. 8, 9 and 10) and CR (Fig. 15), the behavior of 'achievable discharge burnup' (Figs. 11, 12 and 13) is elucidated. In the thermal range, there is a peak in $B_{D}$, the location of which is to the right of the peak for BOL $k_{\infty}$. In the epithermal range, $B_{D}$ exhibits a minimum due to the trade-off between reduced BOL $k_{\infty}$ and improved CR. For $\mathrm{H}_{2} \mathrm{O}$ and $\mathrm{D}_{2} \mathrm{O}-\mathrm{H}_{2} \mathrm{O}$ cooled lattices, it is not worthwhile to operate in the epithermal range under the constraint of a once-through fuel cycle. In the fast range, the effect of $\mathrm{CR}$ is dominant since the initial reactivity is nearly constant.

Fig. 16 shows that for $\mathrm{UO}_{2}$ fuel the neutron spectrum is gradually hardened for lower $\mathrm{H} / \mathrm{HM}$ values, as expected. Since a harder spectrum facilitates the efficient conversion of fertile to fissile material, $\mathrm{CR}$ values are higher in the fast region than in the thermal region (as shown in Fig. 15). 


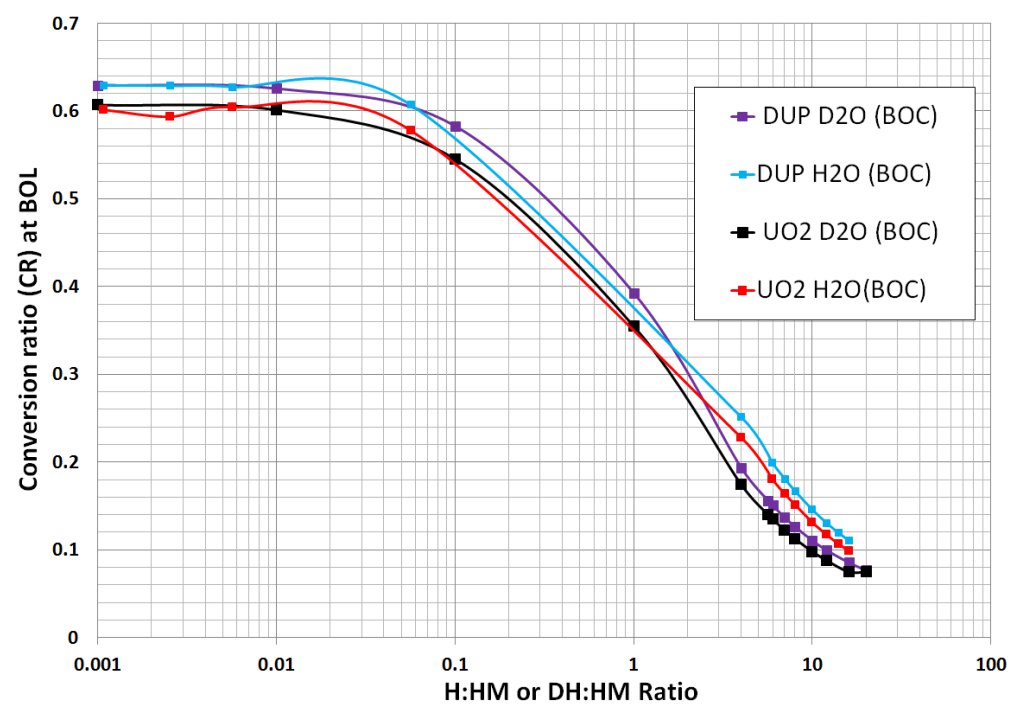

Fig. 15. BOL conversion ratio as a function of $\mathrm{H} / \mathrm{HM}$ or $\mathrm{DH} / \mathrm{HM}$ by varying coolant density.

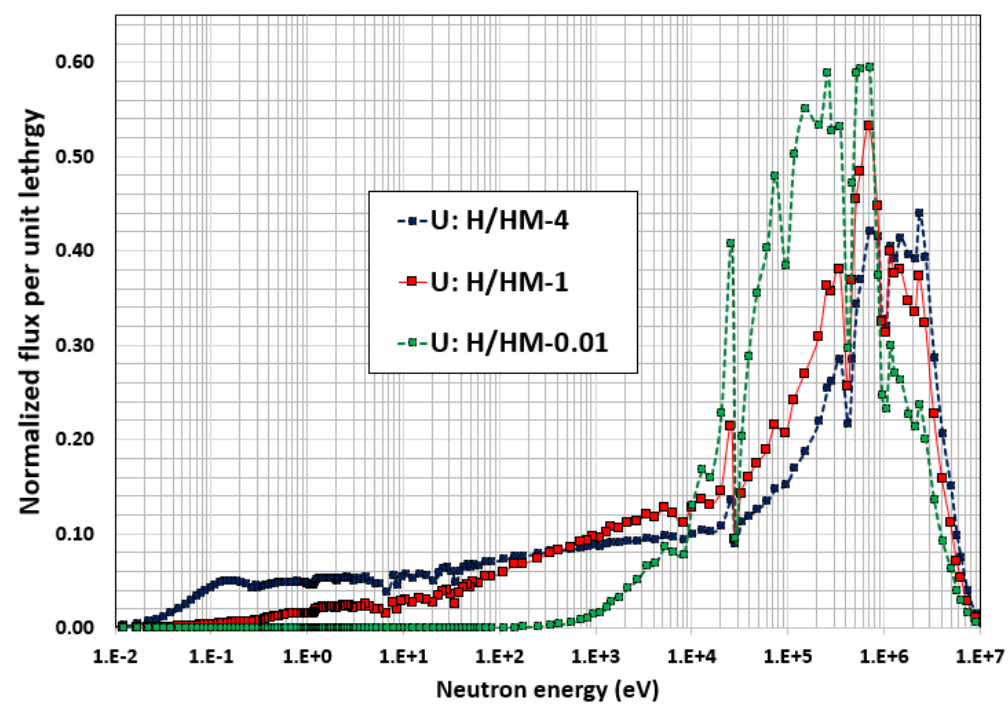

Fig. 16. Normalized flux per unit lethargy at $\mathrm{BOL}$ for $\mathrm{UO}_{2}$ fuel at different $\mathrm{H} / \mathrm{HM}$ by varying coolant density $-\mathrm{H} / \mathrm{HM}$ values of $0.01,1$ and 4 are shown. 


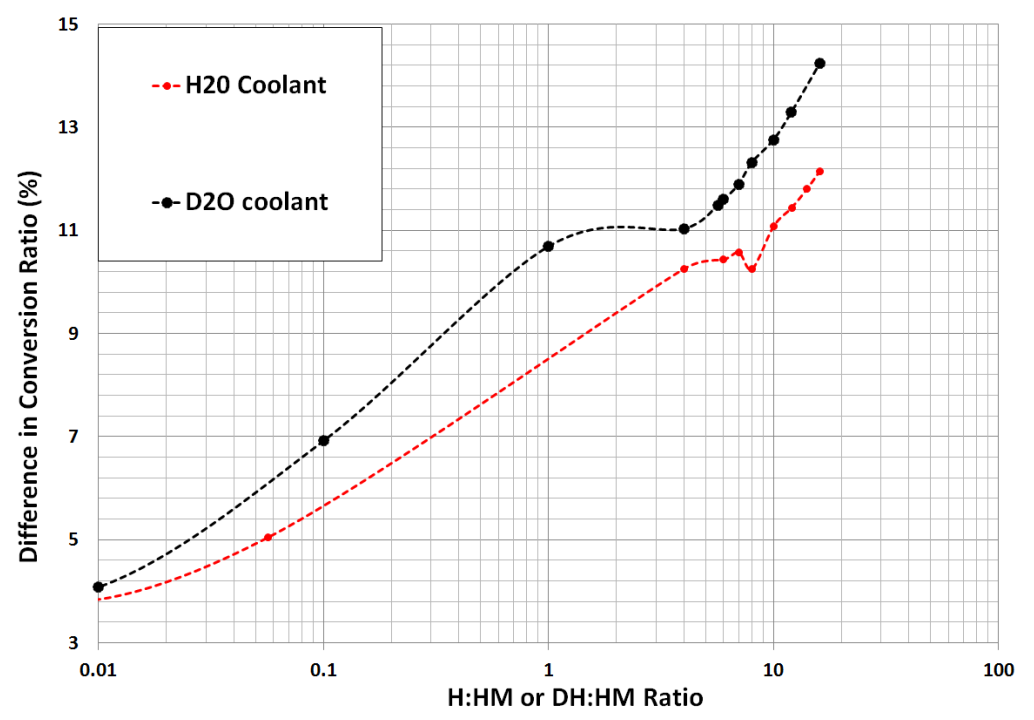

Fig. 17. Difference (\%) in conversion ratio between duplex and $\mathrm{UO}_{2}$ fuels as a function of $\mathrm{H} / \mathrm{HM}$ or $\mathrm{DH} / \mathrm{HM}$ by varying coolant density.

A higher CR is often a design goal. Fig. 17 shows that the CR of the duplex fuel is $\sim 3 \%$, $\sim 8 \%$ and $\sim 10 \%$ higher than that of the all- $\mathrm{UO}_{2}$ fuel in the fast, epithermal and thermal energy ranges, respectively, for both coolants, thus explaining the higher discharge burnup capability of the duplex fuel.

For both fuels, CR is higher for the mixed coolant in the under-moderated region but these values fall dramatically in the over-moderated region $(\mathrm{DH} / \mathrm{HM}>6)$, and in that moderation regime are exceeded by the $\mathrm{CR}$ values for the $\mathrm{H}_{2} \mathrm{O}$ coolant.

The higher $\mathrm{CR}$ of the duplex fuel could facilitate a longer core life, which is a desirable feature for our marine core. The higher $\mathrm{CR}$ also results in a smaller reactivity swing between BOL and EOL, which makes the task of reactivity control of the SBF core easier.

\section{Evaluation of the MTC and Safety Perspective}

It is important to observe the effect of the $\mathrm{H} / \mathrm{HM}$ and $\mathrm{DH} / \mathrm{HM}$ on MTC and how temperature changes in the moderator affect overall reactivity. In our SBF marine core, since the coolant is also the moderator, an increase in reactor power will heat the moderator and reduce the density of moderator atoms via thermal expansion. Thus, an increase in temperature reduces the $\mathrm{H} / \mathrm{HM}$ and $\mathrm{DH} / \mathrm{HM}$ values. This affects the core's reactivity primarily through two distinct, but antagonistic mechanisms (Otto, 2013, Xu, 2003):

1. As the density of moderator decreases, the neutrons have fewer elastic collisions before entering the fuel. They are more likely to enter the fuel in the epithermal energy range and be absorbed in the fuel's resonances. This decreases the resonance escape probability and thus lowers $k_{\infty}$.

2. As the density of the moderator decreases, thermal neutrons are less likely to be parasitically captured in the moderator. This increases the thermal utilization factor 
and thus also $k_{\infty}$.

This has important consequences for reactivity stability and inherent safety. When the first effect outweighs the second, the reactor is under-moderated, and an increase in temperature will decrease reactivity and stabilize the reactor. However, if the second effect outweighs the first, the reactor is over-moderated, and a temperature rise will further increase reactivity and power, leading to positive feedback. Any 'optimization' of the lattice geometry must not breach this threshold and undermine this inherent stability.

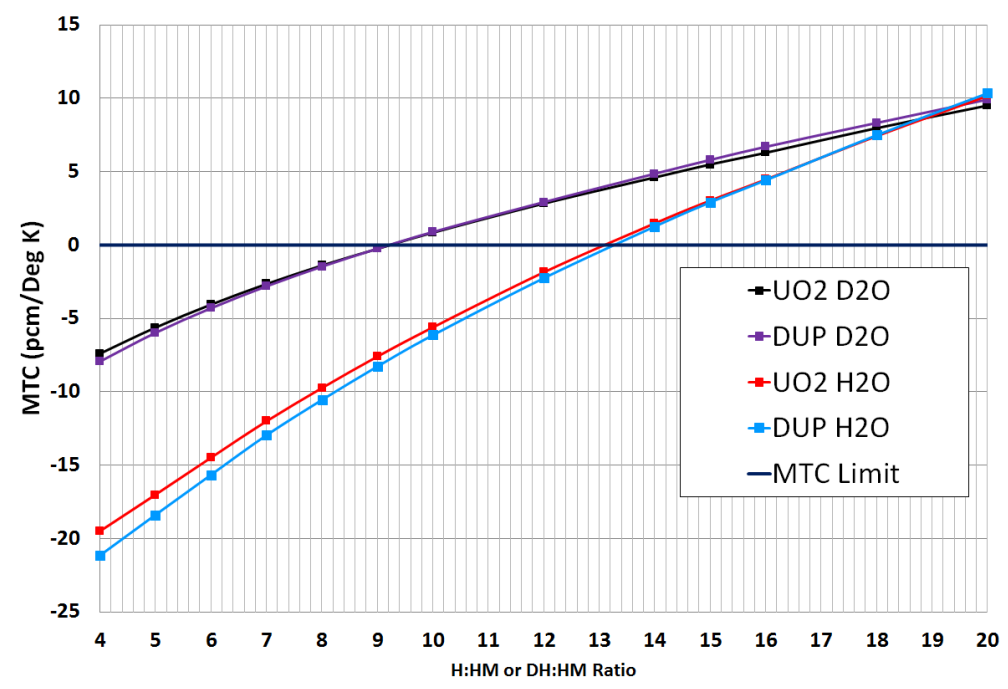

Fig. 18. $\mathrm{MTC}$ as a function of $\mathrm{H} / \mathrm{HM}$ or $\mathrm{DH} / \mathrm{HM}$ by varying pin pitch.

To evaluate $\alpha_{M}$, the MTC, we calculate the BOL reactivity $(\rho)$ for an assembly in two different conditions: first, at the standard moderator temperature $(T)$ of $580 \mathrm{~K}$, and second, with a moderator temperature $(T+\Delta T)$ of $590 \mathrm{~K}$ (and an appropriately adjusted water density). Taking $\alpha_{M} \approx \Delta \rho / \Delta T$, we plot $\alpha_{M}$ against (D)H/HM in Fig. 18. MTC was investigated by varying pin pitch (over the ranges 11.54-19.94 $\mathrm{mm}$ (for $\mathrm{H}_{2} \mathrm{O}$ ) and 12.65-23.08 $\mathrm{mm}$ (for the mixed coolant)), while keeping the fuel pin diameter and coolant density constant at reference values.

SBF operation offers potential safety in the presence of negative MTC over the entire core life. Fig. 18 shows that except at very high (D)H/HM values the MTC is lower (more negative) for the $\mathrm{H}_{2} \mathrm{O}$ coolant. For both fuels, the upper limit on $\mathrm{DH} / \mathrm{HM}$ (for negative MTC) for the mixed coolant is $\sim 9$ and on $\mathrm{H} / \mathrm{HM}$ for $\mathrm{H}_{2} \mathrm{O}$ it is $\sim 13$. For both coolants, for (D) $\mathrm{H} / \mathrm{HM}$ values giving negative MTC, the MTC of the duplex fuel is slightly more negative than that of the $\mathrm{UO}_{2}$ fuel, more so for $\mathrm{H}_{2} \mathrm{O}$.

It is important addressing that since this neutronic study has been performed for the poison-free candidate fuels, the power peaking factors (PPF) won't represent the true values as higher burnable poison loading and control rods will be required to suppress the reactivity for this SBF operation (Alam, 2018, Alam et al., 2015). High thickness IFBA provides different PPF values than the poison-free fuel and might deteriorate the PPFs. Therefore, PPF hasn't been considered in this paper. In addition, peak cladding temperature calculation 
for the poison-free fuels will be misleading since it is required to perform safety analyses for the hottest channel to observe whether all operational safety criteria are met (Alam, 2018, Oliveira, 2016, Todreas and Kazimi, 2012). Through-life hottest channel is identified by finding the pin with the highest power (Todreas and Kazimi, 2012), which is seriously influenced by burnable poison and control rods. Therefore, peak cladding temperature hasnt been considered in this parametric neutronic analyses of poison-free fuels. However, in order to confirm that all the thermal-hydraulic safety constraints are satisfied for both the candidate fuels, 3D neutronic/thermal-hydraulic hot channel analysis has been performed and our study confirmed that thermal-hydraulic design requirements for both the candidate fuels can be met (Alam, 2018).

\section{Conclusions}

This parametric neutronics study shows that, for the candidate fuels for use in a SBF, civil marine SMR core considered

- A higher discharge burnup is achievable in either a wetter-than-normal or much dryerthan-normal lattice, while epithermal lattices are distinctly inferior performers.

- $\mathrm{D}_{2} \mathrm{O}-\mathrm{H}_{2} \mathrm{O}$ coolant is effective for the drier lattices in terms of achieving higher discharge burnup, whereas $\mathrm{H}_{2} \mathrm{O}$ coolant is effective for the wetter lattices.

- Candidate fuels with $\mathrm{D}_{2} \mathrm{O}-\mathrm{H}_{2} \mathrm{O}$ coolant would require higher poison loadings than with $\mathrm{H}_{2} \mathrm{O}$ coolant due to their higher initial reactivity.

- The duplex fuel configuration offers higher discharge burnup potential for all moderation regimes for both coolants due to its higher conversion ratio.

- The duplex fuel lattice would also require less burnable absorber to suppress initial excess reactivity than the all- $\mathrm{UO}_{2}$ fuel.

Future work will include the consideration of alternative cladding materials (e.g. ODS-type steel and $\mathrm{SiC}$ ) for very high burnup fuels and coupled neutronic-thermal-hydraulic studies for heavy water coolants. Since power density is an important figure of merit and characterizes design performance of marine propulsion cores, future work will also focus on the design of a high power density core that fulfills the objective of providing 15 EFPY life.

\section{References}

Alam, S.B., 2018. The Design of Reactor Cores for Civil Nuclear Marine Propulsion. Ph.D. thesis. University of Cambridge. Cambridge, UK.

Alam, S.B., Almutairi, B., Kumar, D., Goodwin, C.S., Alameri, S.A., 2018a. 3D modeling of ReducedModeration Water Reactor lattice for $\mathrm{P}_{0}$ and $\mathrm{P}_{1}$ scattering approximations using deterministic and monte carlo codes, in: Proc. 2018 Pacific Basin Nuclear Conference (PBNC 2018), San Francisco, CA, USA. pp. 285-294. 
Alam, S.B., Almutairi, B., Kumar, D., Goodwin, C.S., Alameri, S.A., 2018b. Convergence studies using method of characteristics solver for the Reduced-Moderation Water Reactor model, in: Proc. 2018 Pacific Basin Nuclear Conference (PBNC 2018), San Francisco, CA, USA. pp. 119-128.

Alam, S.B., Goodwin, C.S., Parks, G.T., 2019. Assembly-level analyses of accident-tolerant cladding concepts for a long-life civil marine SMR core using micro-heterogeneous duplex fuel. Progress in Nuclear Energy $111,24-41$.

Alam, S.B., Lindley, B.A., Parks, G.T., 2015. Feasibility study of the design of homogeneously mixed thorium-uranium oxide and all-uranium fueled reactor cores for civil nuclear marine propulsion, in: Proc. ICAPP 2015, Nice, France. pp. 1918-1927.

Alam, S.B., Lindley, B.A., Parks, G.T., 2016. Neutronic performance of high power density marine propulsion cores using $\mathrm{UO}_{2}$ and microheterogeneous $\mathrm{ThO}_{2}-\mathrm{UO}_{2}$ duplex fuels, in: Proc. PHYSOR 2016, Sun Valley, Idaho, USA. pp. 3519-3531.

Alam, S.B., Ridwan, T., Parks, G.T., Almutairi, B., Goodwin, C.S., 2018c. High power density reactor core design for civil nuclear marine propulsion. Part I: Assembly-level analysis, in: Proc. PHYSOR 2018, Cancun, Mexico. pp. 46-57.

Alam, S.B., Ridwan, T., Parks, G.T., Almutairi, B., Goodwin, C.S., 2018d. High power density reactor core design for civil nuclear marine propulsion. Part II: Whole-core analysis, in: Proc. PHYSOR 2018, Cancun, Mexico. pp. 58-69.

Almutairi, B., Alam, S.B., , Goodwin, C.S., Usman, S., 2018. Benchmarking calculation of a soluble-boron-free SMR lattice model using deterministic, hybrid monte carlo and monte carlo codes, in: Proc. 2018 Pacific Basin Nuclear Conference (PBNC 2018), San Francisco, CA, USA. pp. 136-145.

Brown, N.R., Worrall, A., Todosow, M., 2017. Impact of thermal spectrum small modular reactors on performance of once-through nuclear fuel cycles with low-enriched uranium. Annals of Nuclear Energy $101,166-173$.

Carlton, J., Smart, R., Jenkins, V., 2011. The nuclear propulsion of merchant ships: aspects of engineering, science and technology. J. Mar. Eng. Technol. 10, 47-59.

Clayton, J., 1993. The Shippingport Pressurized Water Reactor and Light Water Breeder Reactor. Technical Report WAPD-T-3007. Westinghouse Electric Corporation, Bettis Atomic Power Laboratory. West Mifflin, Pennsylvania, USA.

Driscoll, M.J., Downar, T.J., Pilat, E.E., 1990. The Linear Reactivity Model for Nuclear Fuel Management. American Nuclear Society, La Grange Park, IL.

Engelder, T.C., 1961. Spectral Shift Control Reactor Basic Physics Program: Critical Experiments on Lattices Moderated by $\mathrm{D}_{2} \mathrm{O}-\mathrm{H}_{2} \mathrm{O}$ Mixtures. volume 1231. Office of Technical Services.

Galperin, A., Shwageraus, E., Todosow, M., 2002. Assessment of homogeneous thorium/uranium fuel for Pressurized Water Reactors. Nucl. Technol. 138, 111-122.

Harvey, C., 2010. At sea over naval HEU: Expanding interest in nuclear propulsion poses proliferation challenges. Nuclear Threat Initiative 29.

Hirdaris, S., Cheng, Y., Shallcross, P., Bonafoux, J., Carlson, D., Prince, B., Sarris, G., 2014. Considerations on the potential use of nuclear small modular reactor (SMR) technology for merchant marine propulsion. Ocean Eng. 79, 101-130.

Hutt, P., 1992. Overview Functional Specification of PANTHER: A Comprehensive Thermal Reactor Code for Use in Design, Assessment and Operation. PANTHER/FSPEC/OVERVIEW 2.0, Nuclear Electric plc, Barnwood, UK.

Ippolito, T.D., 1990. Effects of variation of uranium enrichment on nuclear submarine reactor design. Master's thesis. Massachusetts Institute of Technology.

Kazimi, M., Czerwinski, K., Driscoll, M., Hejzlar, P., Meyer, J., 1999. On the Use of Thorium in Light Water Reactors. Technical Report MIT-NFCTR-016. Department of Nuclear Engineering, Massachusetts Institute of Technology. Cambridge, MA.

Kim, J.C., Kim, M.H., Lee, U., Kim, Y.J., 1998. Nuclear design feasibility of the soluble boron free PWR core. J. Korean Nucl. Soc. 30, 342-352.

Kramer, A., 1962. Nuclear Propulsion for Merchant Ships. US Atomic Energy Commission, Washington, DC. 
Kusunoki, T., Odano, N., Yoritsune, T., Ishida, T., Hoshi, T., Sako, K., 2000. Design of advanced integral-type marine reactor, MRX. Nucl. Eng. Des. 201, 155-175.

Leppänen, J., Pusa, M., 2009. Burnup calculation capability in the PSG2/Serpent Monte Carlo reactor physics code, in: Proc. Int. Conf. Advances in Mathematics, Computational Methods, and Reactor Physics, Saratoga Springs, NY.

Long, D., Richards, S., Smith, P., Baker, C., Bird, A., Davies, N., Dobson, G., Fry, T., Hanlon, D., Perry, R., Shepherd, M., 2015. MONK10: A Monte Carlo code for criticality analysis, in: Proc. Int. Conf. Nuclear Criticality Safety (ICNC 2015), Charlotte, NC. pp. 923-935.

Ma, C., Von Hippel, F., 2001. Ending the production of highly enriched uranium for naval reactors. Nonprolif. Rev. 8, 86-101.

MacDonald, P., Lee, C., 2004. Use of thoria-urania fuels in PWRs: A general review of a NERI project to assess feasible core designs, economics, fabrication methods, in-pile thermal/mechanical behavior, and waste form characteristics. Nucl. Technol. 147, 1-7.

McCord, C., 2013. Examination of the proposed conversion of the US Navy nuclear fleet from highly enriched Uranium to low enriched Uranium. Master's thesis. Massachusetts Institute of Technology.

Nagy, M., Aly, M., Gaber, F., Dorrah, M., 2014. Neutron absorption profile in a reactor moderated by different mixtures of light and heavy waters. Annals of Nuclear Energy 72, 487-496.

Newton, T., Hosking, G., Hutton, L., Powney, D., Turland, B., Shuttleworth, E., 2008. Developments within WIMS10, in: Proc. PHYSOR 2008, Interlaken, Switzerland.

Oliveira, R., 2016. Neutronic Thermal-Hydraulic Coupling of 3D MoC WIMS and Sub-channel Analysis COBRA-EN Codes. Master's thesis. Department of Engineering, University of Cambridge. Cambridge, $\mathrm{UK}$.

Otto, R.T., 2013. Core Optimization in a Thorium-based Civil Marine Propulsion Reactor. Master's thesis. Department of Engineering, University of Cambridge.

Ragheb, M., 2012. Nuclear marine propulsion. University of Illinois at Urbana-Champaign .

Sawyer, G., Shirley, J., Stroud, J., Barlett, E., McKesson, C., 2008. Analysis of high-speed trans-pacific nuclear containership service. USA: General Management Partners LLC .

Schinas, O., Stefanakos, C.N., 2012. Cost assessment of environmental regulation and options for marine operators. Transport. Res. C-Emer. 25, 81-99.

Shwageraus, E., Zhao, X., Driscoll, M.J., Hejzlar, P., Kazimi, M.S., Herring, J.S., 2004. Microheterogeneous thoria-urania fuels for pressurized water reactors. Nucl. Technol. 147, 20-36.

Tochihara, H., Komano, Y., Ishida, M., Narukawa, K., Umeno, M., 1998. Nuclear design for mixed moderator PWR. Progress in Nuclear Energy 32, 533-537.

Todosow, M., Galperin, A., Herring, S., Kazimi, M., Downar, T., Morozov, A., 2005. Use of thorium in light water reactors. Nucl. Technol. 151, 168-176.

Todreas, N.E., Kazimi, M.S., 2012. Nuclear systems. vol. 1, thermal hydraulic fundamentals. FL: CRC Press, Boca Raton, USA.

Winters, J.W., 2004. AP1000 Design Control Document. Westinghouse Electric Company LLC, Pittsburgh, PA.

Xu, Z., 2003. Design strategies for optimizing high burnup fuel in Pressurized Water Reactors. Ph.D. thesis. Massachusetts Institute of Technology. Cambridge, MA.

$\mathrm{Xu}$, Z., Driscoll, M., 1997. Neutron spectrum effects on burnup, reactivity, and isotopics in $\mathrm{UO}_{2} / \mathrm{H}_{2} \mathrm{O}$ lattices. Nucl. Sci. Eng. 141, 175-189.

Zhao, X., 2001. Micro-heterogeneous Thorium Based Fuel Concepts for Pressurized Water Reactors. Ph.D. thesis. Massachusetts Institute of Technology. Cambridge, MA. 